\title{
Protection of Cell Viability and Respiratory Quinone Levels by Carotenoid in Micrococcus lysodeikticus (M. luteus)
}

\author{
By J. A. TURNER AND J. N. PREBBLE* \\ Bedford College, Regent's Park, London NW1 4NS
}

(Received 25 September 1979; revised 20 December 1979)

\begin{abstract}
Viability and respiratory activity of post-exponential phase cultures of Micrococcus lysodeikticus ( $M$. luteus) decreased with time more rapidly in carotenoidless mutants than in a parent pigmented strain. The concentration of menaquinone, the respiratory quinone, was found to be low in carotenoidless mutants and in cultures of the pigmented strain where carotenoid synthesis had been partially blocked by diphenylamine. Cell suspensions incorporated $\left[2-{ }^{14} \mathrm{C}\right] \mathrm{mevalonate}$ into menaquinone. Carotenoidless strains incorporated label at substantially higher rates than did the pigmented wild-type strain. Gently prepared membranes of $M$. lysodeikticus also incorporated mevalonate into menaquinone suggesting that the enzymes for the isoprenoid pathway are bound (loosely) to the membrane. Carotenoidless membranes with low concentrations of menaquinone incorporated radioactivity from $\left[2-{ }^{14} \mathrm{C}\right]$ mevalonate into quinone more rapidly than did membranes from the wild-type. Azide inhibited the incorporation but $n$-heptyl-4-hydroxyquinoline- $N$-oxide did not.

It is concluded that the low concentrations of menaquinone in carotenoidless strains are due to rapid breakdown of the quinone. Carotenoid is therefore seen as protecting menaquinone from breakdown by factors as yet unidentified.
\end{abstract}

\section{INTRODUCTION}

The sturdies of Griffiths et al. (1955) led to the conclusion, more recently developed by Cogdell et al. $(1975,1976)$ and Boucher et al. (1977), that a major function of carotenoids in photosynthetic bacteria is to protect the organism from photo-oxidation catalysed by chlorophyll. It was shown that while carotenoidless strains were killed in the presence of light and oxygen, they grew normally in the light when oxygen was absent. Light and oxygen together were also found to be lethal in carotenoidless mutants of aerobic heterotrophic bacteria such as Micrococcus luteus (Sarcina lutea) which normally contain these pigments (Mathews \& Sistrom, 1960). In M. luteus (S. lutea), where carotenoids have been fully identified by Arpin et al. (1973) and Hertzberg \& Liaaen-Jensen (1977), these pigments protect the respiratory quinone from destruction by visible light (Anwar \& Prebble, 1977). It has generally been assumed in $M$. luteus that, like the photosynthetic bacteria, absence of carotenoid only affects the ability of the organism to survive in light. However, it has recently been observed in our laboratory that carotenoidless strains stored at $4{ }^{\circ} \mathrm{C}$ in the dark lose viability much more rapidly than the parent wild-type strain. Evidence is presented here in support of a new role for carotenoid, namely that the presence of these pigments reduces the rate of quinone breakdown by factors as yet unidentified. In the absence of carotenoid, loss of quinone reduced viability in stationary phase cultures. A preliminary account has appeared (Prebble \& Turner, 1978). 


\section{METHODS}

Strains and growth of bacteria. Micrococcus lysodeikticus (M. luteus) NCTC 2665 was maintained on nutrient agar. Four carotenoidless mutants (UV1, UV2, UV3 and UV4) were obtained by treating the wildtype strain, plated on nutrient agar, with ultraviolet light $(254 \mathrm{~nm})$. After incubation at $26^{\circ} \mathrm{C}$, the identity of the white colonies with the parent strain was checked. The mutants were also found to back mutate slowly. Bacteria were grown in $500 \mathrm{ml}$ nutrient broth shake-cultures $\left(60\right.$ to 70 oscillations $\mathrm{min}^{-1}$ ) overnight at $30^{\circ} \mathrm{C}$ (except where shown otherwise). Cultures were inoculated from a broth pilot culture.

Membrane preparation. Method 1. A $500 \mathrm{ml}$ culture was centrifuged $(13000 \mathrm{~g}, 10 \mathrm{~min})$ and the pellet was resuspended in $20 \mathrm{ml}$ sucrose medium containing $1 \mathrm{M}$-sucrose, $20 \mathrm{~mm}$-Tris/ $\mathrm{HCl}$ buffer $\mathrm{pH} 7.4$ and $5 \mathrm{~mm}-$ $\mathrm{MgCl}_{2}$ ). Then $3.5 \mathrm{mg}$ lysozyme (BDH, 25000 units $\mathrm{mg}^{-1}$ ) was added and the suspension was incubated at $37^{\circ} \mathrm{C}$ for $15 \mathrm{~min}$. The resultant protoplasts were centrifuged $(36000 \mathrm{~g}, 30 \mathrm{~min})$ and the pellet was resuspended in $0.05 \mathrm{M}$-potassium phosphate buffer $\mathrm{pH} 7.0$ in which lysis occurred. The membranes were washed once in buffer.

Method 2. The cell pellet from $500 \mathrm{ml}$ culture was resuspended in $20 \mathrm{ml} 0.05 \mathrm{M}$-potassium phosphate buffer pH 7.0 and 3.5 mg lysozyme was added. The mixture was incubated for $15 \mathrm{~min}$ at $37^{\circ} \mathrm{C}$, the membranes were collected by centrifugation $(36000 \mathrm{~g}, 30 \mathrm{~min}$ ) and resuspended in $0.05 \mathrm{M}$-potassium phosphate buffer $\mathrm{pH} 7 \cdot 0$.

The conversion of the cell suspension to ghost-like membrane suspensions was checked by phase-contrast microscopy.

Respiratory enzyme assays. The oxidation of malate, succinate, lactate and NADH was measured with an oxygen electrode at $30^{\circ} \mathrm{C}$ using an incubation mixture containing $25 \mathrm{~mm}$-organic acid or $0 \cdot 15 \mathrm{~mm}-\mathrm{NADH}$ and $40 \mathrm{~mm}$-potassium phosphate buffer $\mathrm{pH} 7 \cdot 0$. Suspensions of whole organisms or membranes were added

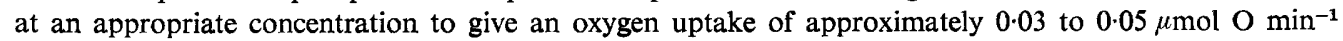
(mg protein $)^{-1}$.

Quinone extraction and assay. Membranes were suspended in approximately $5 \mathrm{ml}$ potassium phosphate buffer $(0.05 \mathrm{M}, \mathrm{pH} \mathrm{7.0)}$ and $16 \mathrm{ml}$ acetone/methanol $(1: 1, \mathrm{v} / \mathrm{v})$ was added. The suspension was shaken vigorously, allowed to stand in the dark for $30 \mathrm{~min}$ and then extracted three times with $10 \mathrm{ml}$ portions of redistilled light petroleum (b.p. 40 to $60^{\circ} \mathrm{C}$ ). The extracts were combined, evaporated to dryness and the residue was dissolved in ethanol for immediate assay or in light petroleum for chromatography.

Quinone was purified by chromatography on a silica gel (Kieselgel 60; Merck, Darmstadt, W. Germany) column shielded from the light (Dunphy \& Brodie, 1971). The sample was added in $2 \mathrm{ml}$ light petroleum. Elution was achieved with $0.5,1 \cdot 0,1.5$ and $2.0 \%(\mathrm{v} / \mathrm{v})$ diethyl ether in redistilled light petroleum. The quinone was eluted in the $2.0 \%$ diethyl ether fraction. Using pure quinones, phylloquinone (vitamin $\mathrm{K}_{1}$ ), menaquinone-7 or menaquinone-8 (vitamins $\mathrm{K}_{2}$ ), 85 to $90 \%$ was recovered in this fraction. A polar fraction containing carotenoid was eluted with methanol but was not analysed further.

The menaquinone was estimated spectrophotometrically by measuring the change in absorbance at 265 and $289 \mathrm{~nm}$ on addition of approximately $0.5 \mathrm{mg}$ sodium borohydride to $3 \mathrm{ml}$ of ethanolic solution containing $0.4 \mathrm{M}$-acetate buffer $\mathrm{pH} \mathrm{5.4}$. The molar difference absorbance coefficient of menaquinone at 265 and $289 \mathrm{~nm}$ is given by $\left(A_{\mathrm{rcd}}-A_{\mathrm{ox}}\right)_{265}-\left(A_{\mathrm{red}}-A_{\mathrm{ox}}\right)_{289}=-14.71 \mathrm{mmol}^{-1} \mathrm{~cm}^{-1}$ (Kroger \& Dadak, 1969).

Carotenoid estimation. An arbitrary absorbance coefficient, $A_{\mathrm{lcm}}^{1 \%}=2500$, was used to estimate the carotenoid concentration in ethanolic or methanolic solutions obtained during quinone separation.

Thin-layer chromatography. Heat-activated $\left(1 \mathrm{~h} \mathrm{at} 110^{\circ} \mathrm{C}\right)$ thin-layer plates of Kieselguhr $\mathrm{G}$ (Merck) with $0.5 \mathrm{~mm}$ layers were dipped in $5 \%(\mathrm{v} / \mathrm{v})$ liquid paraffin in redistilled light petroleum and the petroleum was allowed to evaporate. After addition of samples, plates were run in acetone/water $(95: 5$ or $90: 10, \mathrm{v} / \mathrm{v})$ saturated with $5 \%(\mathrm{v} / \mathrm{v})$ liquid paraffin. Plates were viewed in ultraviolet light to detect spots.

Synthesis of labelled quinone. $\left[2-{ }^{14} \mathrm{C}\right]$ Mevalonate was obtained from The Radiochemical Centre, Amersham, as the mevalonic acid lactone $\left(22 \mathrm{mCi} \mathrm{mmol}^{-1}, 814 \mathrm{MBq} \mathrm{mmol}^{-1}\right)$. Membrane suspensions were incubated with labelled mevalonate (normally $10 \mathrm{~mm}$ and 2 to $10 \mu \mathrm{Ci})$, ATP $(10 \mathrm{~mm})$, NADPH (0.03 mM), $\mathrm{MgCl}_{2}(10$ or $1 \mathrm{~mm}$ ) and potassium phosphate buffer $(0.05 \mathrm{M}, \mathrm{pH} 7 \cdot 0)$. Cell suspensions in phosphate buffer were incubated with labelled mevalonate.

The radioactivity of fractions in organic solvents was measured by scintillation spectrometry. To $1 \mathrm{ml}$ extract was added $10 \mathrm{ml}$ scintillant [containing $40 \mathrm{mg} \mathrm{2,5-diphenyloxazole} \mathrm{and} 1 \mathrm{mg}$ 1,4-di-2-(5-phenyloxazolyl)benzene in toluene]. Radioactivity was assayed with a Packard Tri-carb liquid scintillation counter, model 3375. Corrections were made for quenching, including that due to carotenoid present in some samples.

Protein assay. The protein content of membrane samples was measured by the micro-Kjeldahl method of Jacobs (1959). 


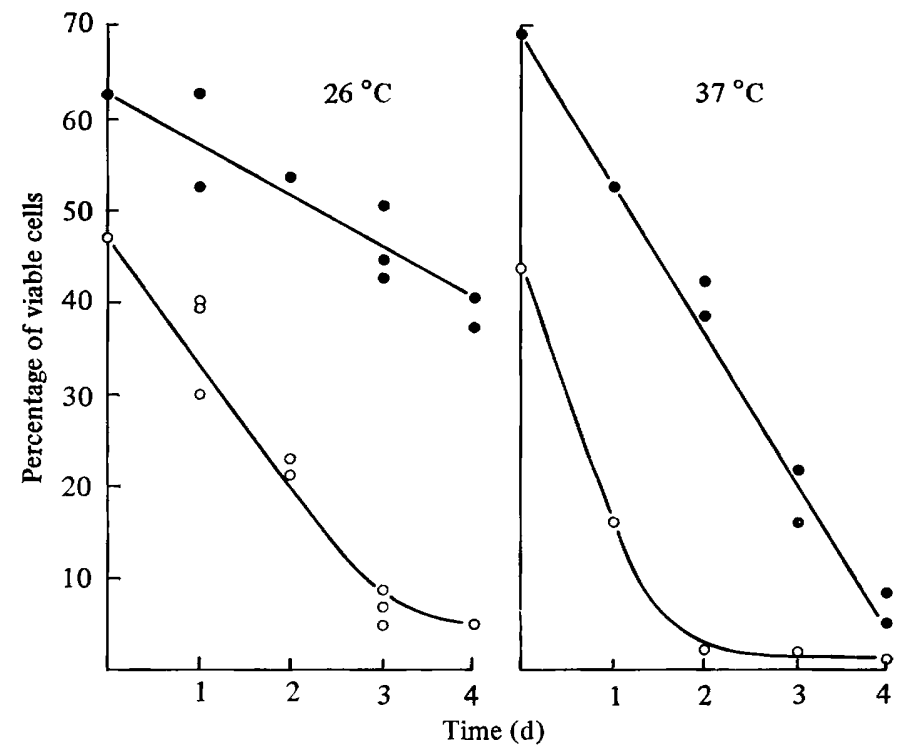

Fig. 1. Viability of the wild-type (O) and carotenoidless mutant (UV1, O) strains of Micrococcus lysodeikticus incubated at 26 and $37^{\circ} \mathrm{C}$. Cells were grown in the dark in nutrient broth shakecultures at the temperature shown. Samples were removed at intervals and diluted to give 1000 cells $\mathrm{ml}^{-1} ; 0 \cdot 1 \mathrm{ml}$ samples of this diluted suspension were plated, incubated at $26^{\circ} \mathrm{C}$ and the colonies were counted after $3 \mathrm{~d}$.

\section{RESULTS}

\section{Properties of the carotenoidless mutants}

Examination of the four ultraviolet-induced mutants showed that none of them synthesized spectrophotometrically detectable carotenoid absorbing in the 400 to $500 \mathrm{~nm}$ region of the spectrum. Two of the mutants (UV2 and UV3) accumulated phytoene which was identified by its absorption spectrum in light petroleum and by co-chromatography on reverse phase thin-layer plates with phytoene purified from tomatoes. Mutants UV1 and UV4 lacked detectable phytoene.

The viability of mutant UV1 was compared with that of the wild-type strain. The viability of both strains grown in nutrient broth shake-cultures had fallen after $1 \mathrm{~d}$ when incubation was at either 26 or $37^{\circ} \mathrm{C}$. Growth of such cultures was complete after about $16 \mathrm{~h}$. In the wild-type, the loss of viability was relatively small at $26^{\circ} \mathrm{C}$, rather greater at $37^{\circ} \mathrm{C}$ (Fig. 1). In the carotenoidless mutant, the loss of viability was substantially greater than in the wildtype at both temperatures.

Measurement of respiratory activities of cell suspensions, which were capable of oxidizing extracellular malate or NADH, were made over a comparable period (Fig. 2). The oxidation of NADH by cell suspensions was unexpected and may reflect a damaged permeability barrier in a proportion of the culture. In both strains a loss of respiratory activity was observed but this was much greater in the mutant strain than in the wild-type. NADH oxidation rates, which are normally much higher than malate oxidation rates, showed a greater loss of activity over the $4 \mathrm{~d}$. Loss of malate oxidase activity did not occur until after $2 \mathrm{~d}$. Comparison of the specific activities of malate, lactate, succinate and NADH oxidases in plasma membranes from cells harvested after $16 \mathrm{~h}$ growth showed that the malate and NADH oxidase activities were lower in carotenoidless membranes than in yellow (wild-type) membranes (Table 1). In contrast, succinate and lactate oxidation was greater in the carotenoidless membranes. 


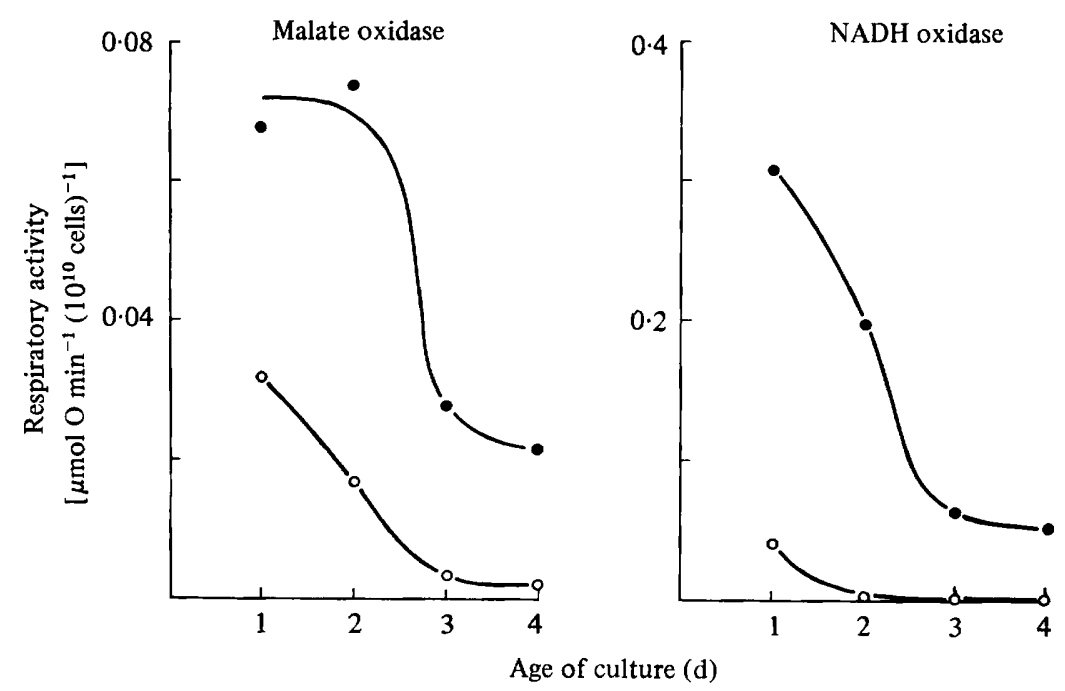

Fig. 2. Respiratory activity of whole organisms of wild-type (๑) and carotenoidless mutant (UV1, O) strains of $M$. lysodeikticus. Cells were grown in nutrient broth shake-cultures at $30^{\circ} \mathrm{C}$.

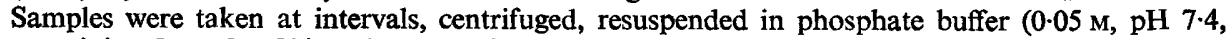
containing $5 \mathrm{~mm}-\mathrm{MgCl}_{2}$ ) and assayed for malate or NADH oxidation.

\section{Table 1. Respiratory activity of membranes prepared from overnight cultures of wild-type and mutant (UV1) strains}

Shake-cultures were grown for $16 \mathrm{~h}$ at $30^{\circ} \mathrm{C}$. Membranes were prepared by method 1 and the oxidase activities were measured at $\mathrm{pH} 7.0$ and $30^{\circ} \mathrm{C}$. The results are the mean of at least 10 preparations.

Enzyme system

NADH oxidase

Malate oxidase

Succinate oxidase

Lactate oxidase

\begin{tabular}{|c|c|}
\hline \multicolumn{2}{|c|}{$\begin{array}{c}10^{3} \times \text { Activity } \\
{\left[\mu \mathrm{mol} \mathrm{O} \min ^{-1}(\text { mg protein })^{-1}\right]}\end{array}$} \\
\hline Wild-type & Mutant UV1 \\
\hline $\begin{array}{c}150 \\
34 \\
2 \cdot 2 \\
4\end{array}$ & $\begin{array}{l}40 \\
16 \\
29 \\
75\end{array}$ \\
\hline
\end{tabular}

Table 2. Menaquinone content of cells and membranes of M. lysodeikticus

Menaquinone was assayed on cells from overnight cultures.

\begin{tabular}{|c|c|c|}
\hline Strain & $\begin{array}{c}10^{11} \times \text { Menaquinone } \\
\text { content per cell } \\
(\mu \mathrm{mol})\end{array}$ & $\begin{array}{l}\text { Menaquinone } \\
\text { content of membranes } \\
\left.[\mu \text { mol (mg protein })^{-1}\right]\end{array}$ \\
\hline Wild-type & $9 \cdot 3$ & 1.52 \\
\hline Mutant UV1 & $3 \cdot 8$ & 0.49 \\
\hline Mutant UV2 & $2 \cdot 0$ & - \\
\hline Mutant UV3 & $3 \cdot 8$ & - \\
\hline Mutant UV4 & $4 \cdot 0$ & - \\
\hline
\end{tabular}

Menaquinone content of pigmented and carotenoidless strains

The respiratory quinone of $M$. lysodeikticus is menaquinone-8 (MK-8) or possibly a closely related menaquinone with one less double-bond in the side-chain, $\mathrm{MK}-8\left(\mathrm{H}_{2}\right)$ (Jeffries $e t$ al., 1967). Studies on the photosensitivity of respiration in another strain of $M$. luteus showed that while the oxidation of NADH and malate required menaquinone, oxidation of succinate and, probably, lactate did not (Anwar \& Prebble, 1977). The results 


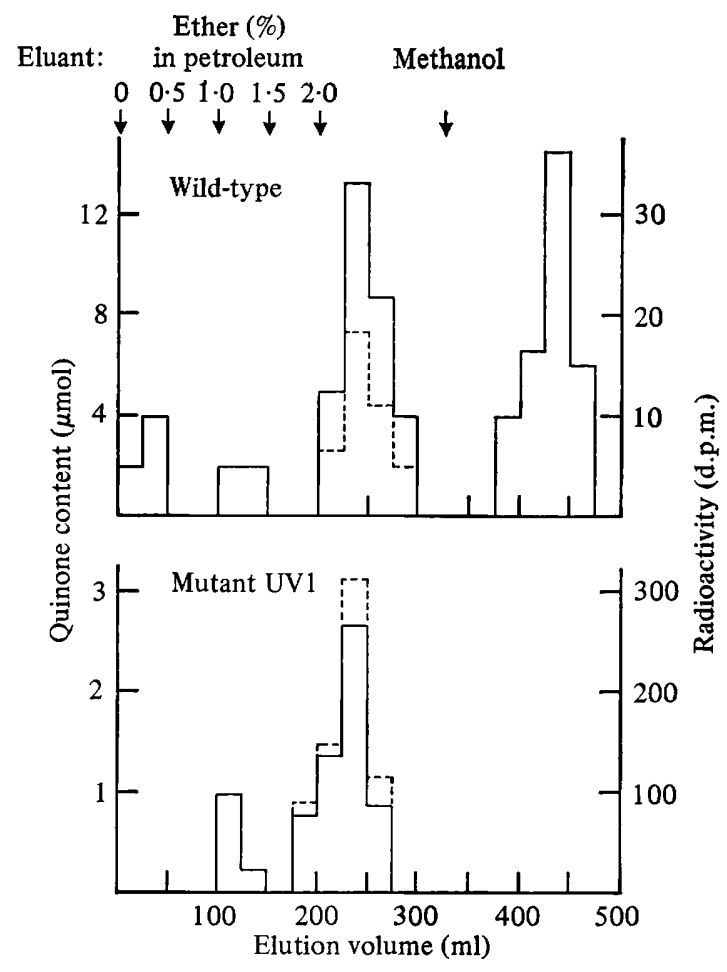

Fig. 3. Elution pattern of radioactivity $(\longrightarrow)$ and quinone $(--)$ from silica gel column chromatography of extracts from wild-type and carotenoidless mutant (UV1) cells. Cultures $(16 \mathrm{~h})$ were centrifuged and the pellets were resuspended in phosphate buffer $(0.05 \mathrm{M}, \mathrm{pH} 7 \cdot 0)$ containing $2 \mu \mathrm{Ci}\left[2-{ }^{14} \mathrm{C}\right]$ mevalonate for $1 \mathrm{~h}$ at $30^{\circ} \mathrm{C}$ with shaking. The cells were then centrifuged, and membranes were prepared and extracted, as described in Methods. The extract in $2 \mathrm{ml}$ light petroleum was added to a silica gel column $(1.2 \times 24 \mathrm{~cm})$ and developed with diethyl ether in petroleum; $25 \mathrm{ml}$ fractions were collected.

of the respiratory measurements suggest that the menaquinone may be deficient in the carotenoidless strains. Table 2 shows that in each mutant strain, the menaquinone level was substantially lower than in the wild-type.

\section{Biosynthesis of menaquinone from $\left[2-{ }^{14} \mathrm{C}\right]$ mevalonate by cell suspensions}

Low concentrations of menaquinone found in carotenoidless cells might be attributed to a low rate of synthesis or a high rate of breakdown. Menaquinone- 8 possesses a side-chain composed of eight isoprenoid units which may be synthesized from mevalonate by the prenyl pyrophosphate pathway. Cell suspensions were incubated with $\left[2-{ }^{14} \mathrm{C}\right]$ mevalonate, membranes were prepared and extracted and the extracts were chromatographed on silica gel (Fig. 3). The major radioactive band was eluted with approximately $2 \%$ diethyl ether in petroleum and coincided with the menaquinone fraction as assayed by the method of Kroger \& Dadak (1969). The fraction had absorption maxima corresponding to those of menaquinone and $95 \%$ of its radioactivity co-chromatographed with pure menaquinone on reverse phase thin-layer chromatography. Both wild-type and UV1 mutant strains gave extracts which included a fraction eluting from the column with about $1 \%$ diethyl ether in petroleum, where the colourless polyene, phytoene, a precursor of coloured carotenoids, also eluted. This fraction from mutant UV1 separated into several bands on thin-layer chromatography. About $25 \%$ of the fraction co-chromatographed with phytoene although phytoene was not detectable spectrophotometrically. In extracts from the wild-type strain 
Table 3. Incorporation of $\left[2-{ }^{14} \mathrm{C}\right]$ mevalonate into quinone by membranes from pigmented wild-type and mutant strains

Membranes from $500 \mathrm{ml}$ culture were prepared by method 1 and resuspended in $10 \mathrm{ml}$ phosphate buffer. The membrane suspension $(10 \mathrm{ml})$ was incubated with $10 \mathrm{mM}-\mathrm{ATP}, 10 \mathrm{mM}-\mathrm{MgCl}_{2}, 30 \mu_{\mathrm{M}-}$ NADPH and $3 \mathrm{~mm}$-mevalonate containing $5 \mu \mathrm{Ci}\left[2-{ }^{14} \mathrm{C}\right] \mathrm{mevalonate}$ (total volume $20 \mathrm{ml}$ ) for $1 \mathrm{~h}$ in a shaking water-bath at $30^{\circ} \mathrm{C}$. The quinone was then extracted, purified and assayed.

\begin{tabular}{lcc} 
Strain & \multicolumn{2}{c}{ Content } \\
Wild-type & $11 \cdot 6$ & $\begin{array}{c}\text { Specific radioactivity } \\
\left(\text { d.p.m. } \mu \text { mol }^{-1}\right)\end{array}$ \\
Mutant UV1 & $3 \cdot 5$ & $3 \cdot 2$ \\
Mutant UV2 & $2 \cdot 2$ & 188 \\
Mutant UV3 & $3 \cdot 5$ & 42 \\
Mutant UV4 & $3 \cdot 1$ & 1651 \\
Muinone & 476
\end{tabular}

Table 4. Menaquinone content of diphenylamine-treated cells

Cultures were grown in the presence of $60 \mu \mathrm{M}$-diphenylamine and membranes were prepared by method 1 . The membranes were incubated with $10 \mathrm{~mm}$-mevalonate containing $5 \mu \mathrm{Ci}\left[2-{ }^{14} \mathrm{C}\right]$ mevalonate, $10 \mathrm{~mm}$-ATP, $30 \mu \mathrm{M}-\mathrm{NADPH}$ and $10 \mathrm{mM}-\mathrm{MgCl}_{2}$ for $1 \mathrm{~h}$ in a shaking water-bath at $30^{\circ} \mathrm{C}$. The concentration of quinone, its specific radioactivity and the radioactivity of the phytoene- and carotenoid-containing fractions were then assayed. Wild-type and UV1 mutant strains were treated similarly as controls.

Culture

$\overbrace{\begin{array}{c}\text { Content } \\ (\mu \mathrm{mol} \text { per } 500 \mathrm{ml} \text { culture) }\end{array}}^{\begin{array}{c}\text { Specific radioactivity } \\ \left.\text { (d.p.m. } \mu \mathrm{mol}^{-1}\right)\end{array}}$

8.9

$2 \cdot 3$

$1 \cdot 1$
Radioactivity in phytoene fraction (d.p.m. per $500 \mathrm{ml}$ culture)

\section{$5 \cdot 0$}

31

93
Radioactivity in carotenoid fraction (d.p.m. per $500 \mathrm{ml}$ culture)

0 594

138

41

substantial amounts of radioactivity were found in the polar fraction which eluted with methanol and contained carotenoids. Table 2 shows that a much greater amount of $\left[2-{ }^{14} \mathrm{C}\right]-$ mevalonate was incorporated into quinone by the carotenoidless cells than by the wild-type cells. Later experiments showed that inclusion of $50 \mathrm{~mm}$-succinate in the incubation medium could increase the incorporation of label from mevalonate into menaquinone in the wildtype by 10 - to 20 -fold.

\section{Biosynthesis of menaquinone from $\left[2-{ }^{14} \mathrm{C}\right]$ mevalonate by membrane suspensions}

Preparations of plasma membranes also incorporated $\left[2-{ }^{14} \mathrm{C}\right]$ mevalonate into menaquinone, although this biosynthetic activity varied, particularly when method 2 was used to prepare the membranes, suggesting loose binding of some of the enzymes involved. In mutant UV1, substantial incorporation of activity into quinone required ATP and NADPH. Initially $10 \mathrm{mM}-\mathrm{MgCl}_{2}$ was also added as recommended by other workers (e.g. Kandutsch et al., 1964; Sagami et al., 1977) but later it was found that this concentration was inhibitory and $1 \mathrm{mM}-\mathrm{MgCl}_{2}$ gave much better incorporation. Incorporation of radioactivity from labelled mevalonate was substantially lower in membranes from the wild-type than in those from any of the mutant strains (Table 3). Addition of the supernatant from the yellow cells increased incorporation but did not account for the differences between white and yellow membranes. Less activity was found in the quinone when labelled isopentenyl pyrophosphate was used as substrate (results not shown) but again incorporation of radioactivity into quinone was greater in membranes from the mutant. 


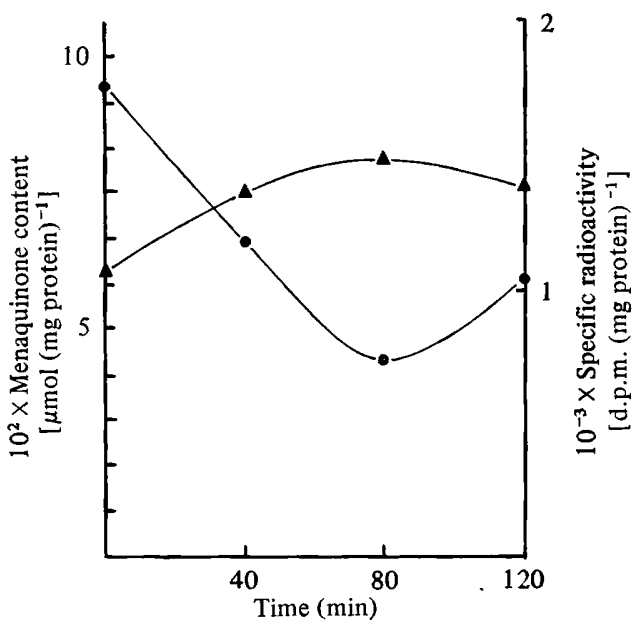

Fig. 4. Concentration ( $\mathbf{O})$ and radioactivity $(\boldsymbol{\Lambda})$ of menaquinone in isolated membranes of a carotenoidless mutant (UV1) maintained in shaken suspension at $30^{\circ} \mathrm{C}$. Cells were labelled by incubation with $10 \mu \mathrm{Ci}\left[2-{ }^{14} \mathrm{C}\right]$ mevalonate in the presence of $0.05 \mathrm{M}$-succinate in phosphate buffer $(0.05 \mathrm{M}, \mathrm{pH} 7.0)$ for $1.5 \mathrm{~h}$. Membranes were prepared (method 2), washed twice and incubated with shaking in phosphate buffer $\mathrm{pH} 7.0$ at $30^{\circ} \mathrm{C}$. Samples were taken at intervals and the concentration and radioactivity of menaquinone were assayed.

Cultures of $M$. lysodeikticus with low concentrations of carotenoids may be prepared by growing cells in the presence of diphenylamine, an inhibitor of the terminal steps of carotenoid synthesis. A final concentration of $60 \mu \mathrm{M}$-diphenylamine in nutrient broth shakecultures substantially reduced the concentration of carotenoid without appreciably inhibiting growth. Membranes from a diphenylamine-treated wild-type culture were examined for their quinone content and their ability to synthesize menaquinone from mevalonate (Table 4). Incorporation of activity into the carotenoid-containing fraction was substantially reduced in diphenylamine-treated cells while the activity in the quinone and in the phytoenecontaining fractions was increased. The concentration of quinone was substantially reduced in the diphenylamine-treated cells showing that they behave like the carotenoidless mutant.

Quinone turnover could be demonstrated in isolated membranes. Washed, labelled membranes were prepared from carotenoidless cells which had been preincubated with $\left[2-{ }^{14} \mathrm{C}\right]-$ mevalonate and succinate. Incubation of such membranes in buffer for up to $2 \mathrm{~h}$ showed a fall in quinone content coupled with an increase in the radioactivity of the quinone (Fig. 4). The results suggest that labelled precursors of menaquinone were bound to the membrane preparation since activity in the quinone continued to increase after the radioactive substrate had been removed.

\section{Effect of naphthoquinone on incorporation of $\left[2-{ }^{14} \mathrm{C}\right]$ mevalonate}

The above results suggest that there is strong regulation of the menaquinone biosynthetic pathway such that in the wild-type strain synthesis is strongly repressed. The effect of two naphthoquinones on biosynthesis was examined. Menadione lacks the isoprenoid side-chain and could either act as a substrate for menaquinone synthesis and might stimulate isoprenoid side-chain formation, or it might mimic menaquinone as an end-product inhibitor of biosynthesis. The latter role could be tested by addition of menaquinone. Table 5 shows that menaquinone-7 added as a dispersion in buffer did have a small repressing effect on incorporation of mevalonate into both the menaquinone and the phytoene fraction. It should be noted that the insolubility of menaquinone in aqueous systems will make it difficult to raise the level of membrane-bound menaquinone by an adequate amount. 


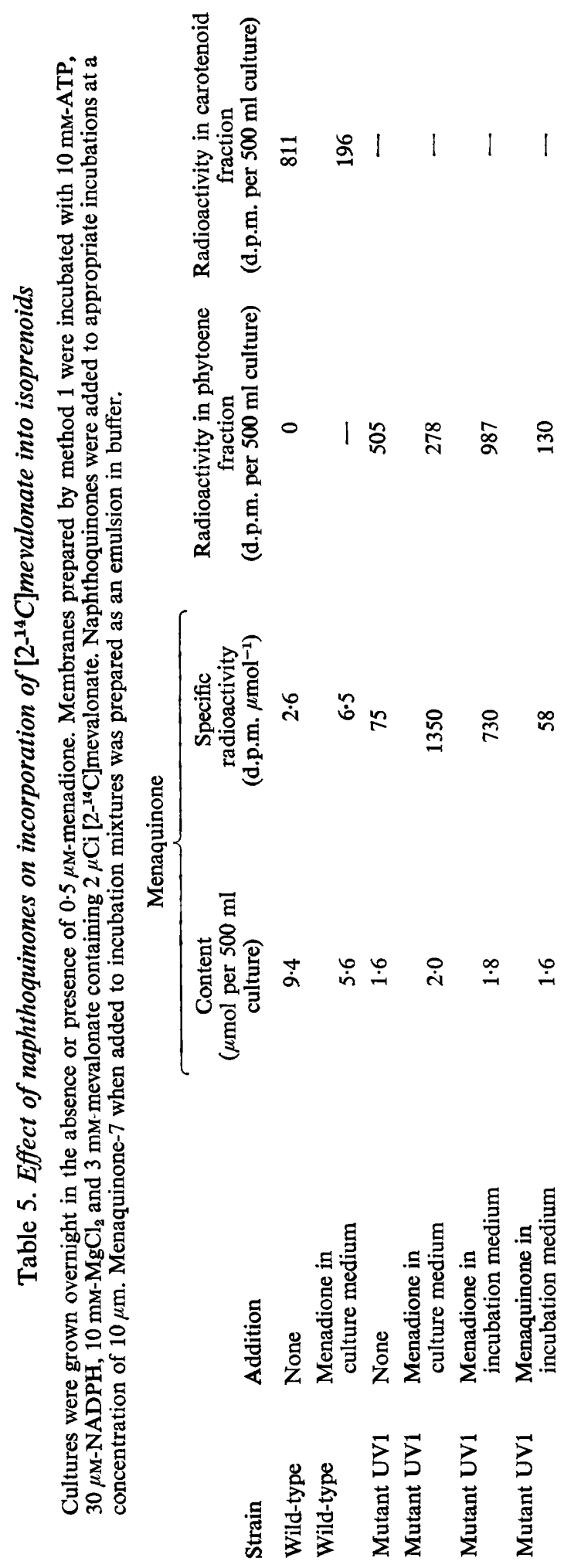




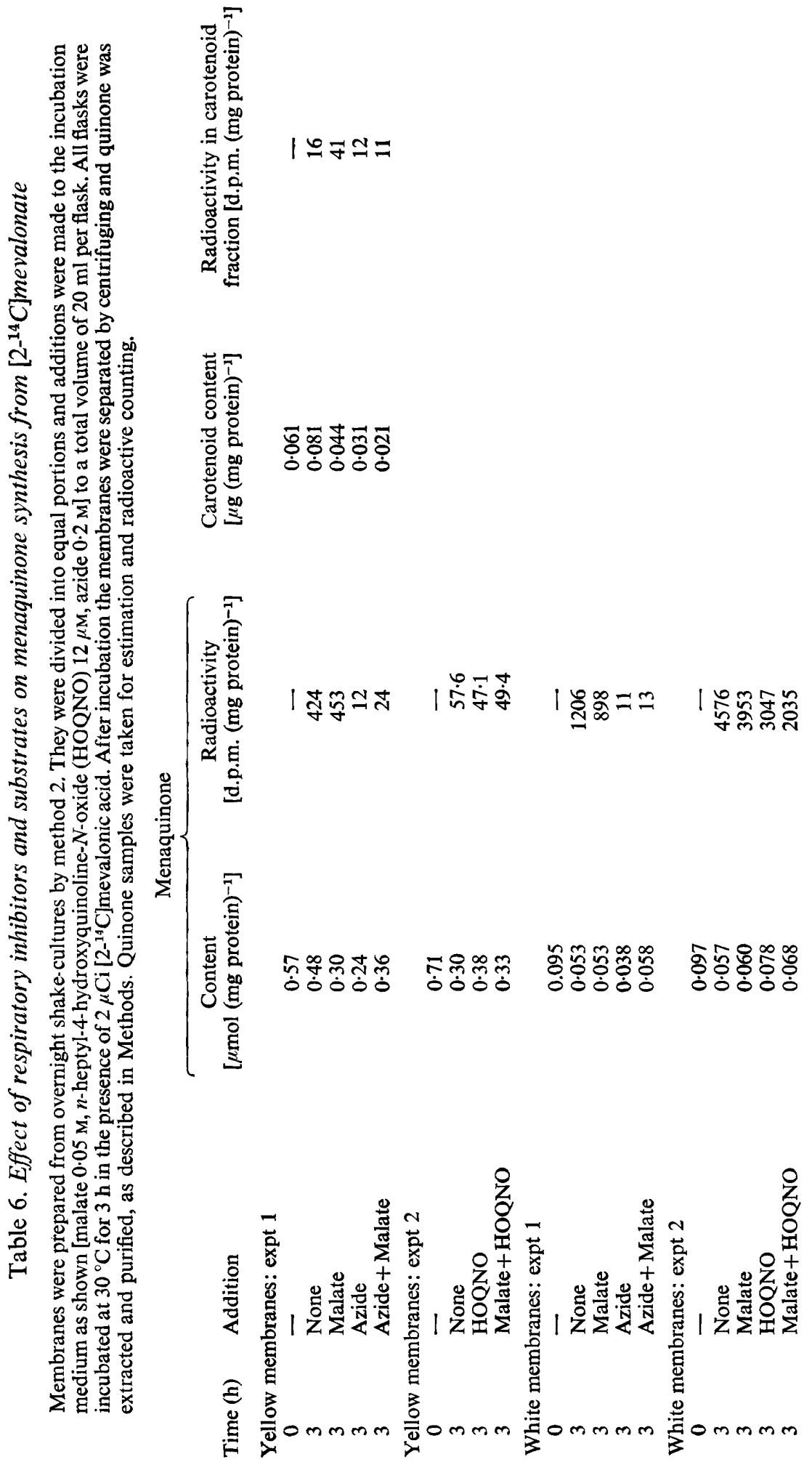




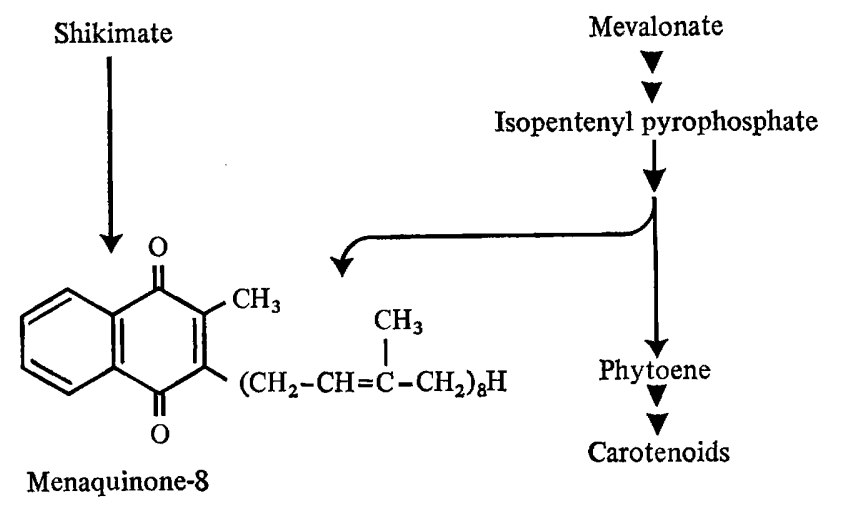

Fig. 5. Relationship between the synthesis of carotenoids and menaquinone.

Menadione, which is relatively soluble, stimulated the incorporation of mevalonate into menaquinone regardless of whether it was added to the growth medium or to the incubation mixture. The results suggest that menadione has an inductive effect on biosynthesis since, when it is present in the growth medium, the membranes have a greater ability to incorporate mevalonate. When present in the incubation medium it also increased incorporation, possibly acting as substrate.

\section{Effect of the state of the respiratory chain on the incorporation of mevalonate}

The level of oxidation of the menaquinol/menaquinone couple can be altered by the use of respiratory inhibitors and substrates. The effect of azide and $n$-heptyl-4-hydroxyquinoline$N$-oxide (HOQNO) in conjunction with malate was investigated. Incubation of membranes for $3 \mathrm{~h}$ with mevalonate resulted in a loss of quinone but an increase in carotenoid (Table 6). Azide was a potent inhibitor of synthesis of menaquinone in both yellow and white membranes. In white membranes, malate and HOQNO tended to inhibit incorporation of label into menaquinone, suggesting that the reduced state decreased the rate of quinone synthesis.

\section{DISCUSSION}

In M. lysodeikticus, the loss of carotenoid, either by mutation or by inhibition of synthesis, is correlated with a substantially increased capacity to convert mevalonate to menaquinone. However, menaquinone concentrations in the absence of carotenoid are low. Hence it must be concluded that there is an increased rate of quinone breakdown in the absence of carotenoid. In stationary phase cultures the rate of biosynthesis is decreased so that the resultant low concentrations of quinone will probably be inadequate for respiratory activity and a rapid loss of viability in the culture will result. It appears that the rate of quinone synthesis in white cells is probably adequate for normal growth in the exponential phase under the highly favourable conditions of laboratory culture. However, in its natural environment, possession of carotenoid will be essential for survival. This is a further reason, in addition to protection from photochemical reactions, why carotenoidless strains are not found in the wild (Anwar et al., 1977; Krinsky, 1976).

The relationship between carotenoid synthesis and menaquinone synthesis is shown in Fig. 5. The reason for increased synthesis in white strains does not appear to be solely due to diversion of metabolic intermediates from carotenoid synthesis to synthesis of the menaquinone side-chain since the incorporation of activity into the carotenoid fraction is similar to that in menaquinone in the wild-type. In white cells the rate of menaquinone synthesis can be ten times that in yellow strains and exceeds the sum of both carotenoid and menaquinone side-chain synthesis. It must therefore be assumed that in yellow cells the rate 
of synthesis is regulated by some sort of end-product inhibition. In white strains, with low quinone concentrations and without inhibition, there is a near maximal rate of synthesis. The difficulty of incorporating the insoluble end-product, menaquinone, into the membrane has so far prevented a really convincing demonstration of end-product inhibition. However, $25 \%$ inhibition has been observed in white membranes. The more soluble menadione appears to act as a substrate for menaquinone synthesis providing the naphthol ring to which the isoprenoid side-chain is added. This is supported by Goldenbaum et al. (1975) who concluded that menadione was able to act as a precursor of menaquinone in a mutant of Staphylococcus aureus. An alternative function of menadione which cannot be ruled out in these studies is as an activator of side-chain synthesis; indeed, the enhancing effect of menadione on the incorporation of mevalonate when menadione is added to the culture medium would support an activating role.

Of particular interest is the existence of an inhibitor for the isoprenoid pathway, azide, which blocks incorporation of labelled mevalonate into menaquinone. This effect appears to be independent of the inhibitory effect of azide on respiration since HOQNO, another inhibitor of the chain, does not have a comparable effect either in the presence or absence of the respiratory substrate malate.

The cause of menaquinone breakdown is not clear. Since it is induced in carotenoidless systems by mutation or by specific inhibition of carotenoid synthesis, enzymic destruction seems unlikely. The possibility of oxidation by singlet oxygen, known to be quenched by carotenoid (Foote \& Denny, 1968; Anderson \& Krinsky, 1973) might be considered. It must be concluded that $M$. lysodeikticus ( $M$. luteus) possesses a double mechanism for protecting itself against the instability of its respiratory quinone. The presence of carotenoid normally ensures that the breakdown of quinone occurs at a limited rate. In the absence of these pigments the cell possesses a strong biosynthetic system for menaquinone synthesis which ensures its survival in favourable conditions. It is this latter capacity for rapid synthesis which has masked the role of carotenoid in earlier studies on M. luteus. Only in stationary phase cultures does the loss of carotenoid seriously affect the viability of the organism.

Is the rapid turnover of menaquinone the only difference between carotenoid-containing and carotenoidless cells? This question remains an open one although we have observed that our mutants, but not the wild-type, fail to form small vesicles by the method of Ishikawa \& Lehninger (1962). Whether this is due to a change in membrane structure induced solely by events associated with, or initiated by, menaquinone breakdown is not clear. Mathews-Roth \& Krinsky (1970) failed to find any evidence for carotenoid stabilization of membranes of $M$. luteus, although carotenoidless cells lysed more readily according to Salton \& Freer (1965).

The ability of membranes to incorporate mevalonate into menaquinone suggests that the enzymes for this pathway are bound to the membrane, at least loosely. This result appears to be at variance with the studies of Kurokawa et al. (1971). Sagami et al. (1978) and Allen et al. (1967) in $M$. luteus who found the polyisoprenoid-synthesizing systems to be soluble, although they are membrane-bound in Lactobacillus plantarum (Allen et al., 1976). Since the products of the isoprenoid pathway are found almost exclusively in the membrane, attachment of the pathway enzymes to the membrane surface would not be surprising. The possibility of specific attachment to the membrane of the enzymes for isoprenoid synthesis is under investigation.

We wish to acknowledge a generous gift of menaquinone-8 from Hoffmann La Roche, Basel, and of menaquinone-7 from Dr G. Britton of Liverpool University. 


\section{REFERENCES}

Allen, C. M., Alworth, W., Macrae, A. \& BLoCH, K. (1967). A long-chain terpenyl pyrophosphate synthetase from Micrococcus lysodeikticus. Journal of Biological Chemistry 242, 1895-1902.

Allen, C. M., Keenan, M. V. \& SaCK, J. (1976). Lactobacillus plantarum undecaprenyl pyrophosphate synthetase. Purification and reaction requirements. Archives of Biochemistry and Biophysics 175, 236-248.

ANDERson, S. M. \& KRINSKy, N. I. (1973). Protective action of carotenoid pigments against photodynamic damage to liposomes. Photochemistry and Photobiology 18, 403-408.

Anwar, M. \& Prebile, J. (1977). The photoinactivation of the respiratory chain in Sarcina lutea (Micrococcus luteus) and protection by endogenous carotenoid. Photochemistry and Photobiology 26, 475-481.

Anwar, M., Hasan-Khan, T., Prebble, J. \& ZAGALSKY, P. F. (1977). Membrane-bound carotenoid in Micrococcus luteus protects naphthoquinone from photodynamic action. Nature, London 270, 538-540.

Arpin, N., Norgard, S., Francis, G. W. \& LiAAEN-JENSEN, S. (1973). Bacterial carotenoids XLI. $\mathrm{C}_{50}$ carotenoids $11 . \mathrm{C}_{45}$ and $\mathrm{C}_{50}$ carotenoids from Sarcina lutea-sarcinaxanthin. Acta chemica scandinavica B27, 2321-2334.

Boucher, F., VAN der Rest, M. \& Gingras, G. (1977). Structure and function of carotenoids in the photoreaction center from Rhodospirillum rubrum. Biochimica et biophysica acta 461, 339357.

Cogdell, R. J., Monger, T. C. \& Parson, W. W. (1975). Carotenoid triplet states in reaction centres from Rhodopseudomonas sphaeroides and Rhodospirillum rubrum. Biochimica et biophysica acta 408, 189-199.

Ccgdell, R. J., Parson, W. W. \& Kerr, M. A. (1976). The type, amount, location and energy transfer properties of the carotenoid in reaction centres from Rhodopseudomonas sphaeroides. Biochimica et biophysica acta 430, 83-93.

Dunphy, P. J. \& Brodie, A. F. (1971). The structure and function of quinones in respiratory metabolism. Methods in Enzymology 18C, 407-461.

Foote, C. S. \& DeNNY, R. W. (1968). Chemistry of singlet oxygen VII. Quenching by $\beta$-carotene. Journal of the American Chemical Society 90 , 6233-6235.

Goldenbaum, P. E., Keyser, P. D. \& White, D. C. (1975). Role of vitamin $K_{2}$ in the organisation and function of Staphylococcus aureus membranes. Journal of Bacteriology 121, 442-449.

Griffiths M., Sistrom, W. R., Cohen-Bazire, G., Stanier, R. Y. \& Calvin, M. (1955). Function of carotenoids in photosynthesis. Nature, London 176, 121 :-1215.
Hertz berg, S \& LlaAen-Jensen, S. (1977). Bacterial carotenoids LIII. $C_{50}$ carotenoids 19. Absolute configuration of sarcinaxanthin and sarcinaxanthin mono- $\beta$-D-glucoside. Isolation of sarcinaxanthin diglucoside. Acta chemica scandinavica B31, 215-218.

IsHIKAWA, S. \& LEHNINGER, A. L. (1962). Reconstitution of oxidative phosphorylation in preparations from Micrococcus lysodeikticus. Journal of Biological Chemistry 237, 2401-2408.

JACOBS, S. (1959). Determination of nitrogen in proteins by means of indanetrione hydrate. Nature, London 183, 262.

Jefrries, L., Cawthorne, M. A., Harris, M., Diplock, A. T., Green, J. \& Price, S. A. (1967). Distribution of menaquinones in aerobic Micrococcaceae. Nature, London 215, 257-259.

Kandutsch, A. A., Paulus, A., Levin, E. \& Bloch, K. (1964). Purification of geranylgeranyl pyrophosphate synthetase from Micrococcus lysodeikticus. Journal of Biological Chemistry 239, 2507-2515.

KRINSKY, N. I. (1976). Cellular damage initiated by visible light. Symposia of the Society for General Microbiology 26, 209-239.

KROGER, A. \& DADAK, V. (1969). On the role of quinones in bacterial electron transport. The respiratory system of Bacillus megaterium. European Journal of Biochemistry 11, 328-340.

Kurokawa, T., Ogura, K. \& Seto, S. (1971). Formation of polyprenyl phosphates by a cell-free enzyme of Micrococcus lysodeikticus. Biochemical and Biophysical Research Communications 45, 251-257.

Mathews, M. M. \& Sistrom, W. R. (1960). The function of carotenoid pigments of Sarcina lutea. Archiv für Mikrobiologie 35, 139-146.

Mathews-Roth, M. M. \& KrinsKY, N. I. (1970). Carotenoid pigments and the stability of the cell membrane of Sarcina lutea. Biochimica et biophysica acta 203, 357-359.

Prebble, J. \& Turner, J. (1978). Protection of endogenous quinone in Micrococcus lysodeikticus by carotenoid in the dark. Fifth International Symposium on Carotenoids, Abstracts p. 59.

Sagami, H., Ogura, K. \& Seto, S. (1977). Solanesyl pyrophosphate synthetase from Micrococcus lysodeikticus. Biochemistry 16, 4616-4622.

Sagami, H., Ogura, K. \& Seto, S. (1978). A new prenyl transferase from Micrococcus lysodeikticus. Biochemical and Biophysical Research Communications 85, 572-578.

Salton, M. R. J. \& Freer, J. H. (1965). Composition of the membranes isolated from several gram-positive bacteria. Biochimica et biophysica acta 107, 531-538. 